J. Lake Sci. (湖泊科学), 2011, 23(6): 974-981

http: //www.jlakes.org. E-mail : jlakes@niglas.ac.cn

(c) 2011 by Journal of Lake Sciences

\title{
新疆乌伦古湖大型底栖无脊椎动物的群落结构”
}

\author{
赵永晶 ${ }^{1}$, 李 鸿 $^{2}$, 王 腾 ${ }^{1}$, 刘 宇 $^{1}$, 刘其根 ${ }^{3}$, 刘 军 $^{4}$, 郝志才 ${ }^{4}$, 朱湘强 ${ }^{4}$, 沈建忠 ${ }^{1 * *}$ \\ (1: 华中农业大学水产学院, 武汉 430070) \\ (2: 湖南省水产科学研究所, 长沙 410153) \\ (3: 上海海洋大学生命科学学院, 上海 200090) \\ (4: 新疆福海水产局, 福海 836400$)$
}

\begin{abstract}
摘 要: 乌伦古湖是我国十大内陆淡水湖之一, 同时也是新疆维吾尔自治区的第二大湖泊和主要渔业基地. 近年来, 随着 气候变化和人为因素的影响, 湖区水体营养状况、生物群落组成等均发生了较大变化. 为揭示该湖大型底栖无脊椎动物 的群落结构特征及其对生态系统变化的响应,2006 年 11 月至 2008 年 7 月设 28 个采样点对大型无脊椎底栖动物的群落 结构特征进行了季节性调查分析. 共采集到底栖动物 87 种, 其中水生昆虫 61 种, 占种类总数的 $70.1 \%$, 寡毛类 14 种, 占 总种数 $16.2 \%$, 软体动物 7 种, 占总种数的 $8.0 \%$, 其它类 5 种, 占总种数的 $5.7 \%$. 大型底栖无脊椎动物年平均密度为 $1015.01 \mathrm{ind} . / \mathrm{m}^{2}$, 年平均生物量为 $9.83 \mathrm{~g} / \mathrm{m}^{2}$. 各季度大型底栖动物的密度表现为冬季 $\left(1234.96 \mathrm{ind} . / \mathrm{m}^{2}\right)>$ 春季 $\left(1044.47 \mathrm{ind} . / \mathrm{m}^{2}\right)>$ 秋季 $\left(931.16 \mathrm{ind} . / \mathrm{m}^{2}\right)>$ 夏季 $\left(849.44 \mathrm{ind} . / \mathrm{m}^{2}\right)$, 生物量同样表现为冬季 $\left(13.54 \mathrm{~g} / \mathrm{m}^{2}\right)>$ 春季 $\left(12.01 \mathrm{~g} / \mathrm{m}^{2}\right)>$ 秋季 $\left(8.37 \mathrm{~g} / \mathrm{m}^{2}\right)>$ 夏季 $\left(5.02 \mathrm{~g} / \mathrm{m}^{2}\right)$. Shannon-Wiener 多样性指数年均值为 2.19 , Margalef 丰富度指数 年均值为 1.34 . 相关分析表明, 水深是影响大型底栖无脊椎动物密度和生物量分布的关键因子.
\end{abstract}

关键词: 乌伦古湖; 大型底栖无脊椎动物;群落结构;多样性指数;相关分析

\section{Community structure of benthic macroinvertebrates in Lake Ulungur in Xinjiang}

ZHAO Yongjing ${ }^{1}$, LI Hong ${ }^{2}$, WANG Teng ${ }^{1}$, LIU Yu ${ }^{1}$, LIU Qigen ${ }^{3}$, LIU Jun ${ }^{4}$, HAO Zhicai ${ }^{4}$, ZHU Xiangqiang $^{4} \&$ SHEN Jianzhong ${ }^{1}$

(1: Ministry of Agriculture College of Fisheries, Huazhong Agricultural University, Wuhan 430070, P. R. China)

(2: Hunan Fisheries Science Institute, Changsha 410153, P. R. China)

(3: College of Aqua-life Science and Technology, Shanghai Ocean University, Shanghai 200090, P. R. China)

(4: Aquatic Bureau of Fuhai of Xinjiang Uygur Autonomous Region, Fuhai 836400, P. R. China)

Abstract: Lake Ulungur is the second largest lake of Xinjiang Uigur Autonomous Region and one of the ten largest freshwater lakes in China. With the impact of human activities and climate variation, nutrients and biotic communities in the lake have been changed obviously. To understand the community of benthic macroinvertebrates and its response to the changes in their environment, we surveyed the benthic macroinvertebrates community in Lake Ulungur seasonally from Nov. 2006 to July 2008. In total, 87 taxa were recorded, including 61 Insecta (70.1\%), 14 Oligochaeta (16.2\%), 7 Mollusca ( $8.0 \%$ ) and other 5 taxa $(5.7 \%)$. The annual density and biomass averaged $1015.01 \mathrm{ind} . / \mathrm{m}^{2}$ and $9.83 \mathrm{~g} / \mathrm{m}^{2}$, respectively. The density was highest in winter $\left(1234.96\right.$ ind. $\left./ \mathrm{m}^{2}\right)$, followed by spring $\left(1044.47 \mathrm{ind} . / \mathrm{m}^{2}\right)$ and autumn $\left(931.16 \mathrm{ind} . / \mathrm{m}^{2}\right)$, and lowest in summer $\left(849.44\right.$ ind $\left./ \mathrm{m}^{2}\right)$. The biomass of benthic macroinvertebrates was highest in winter $\left(13.54 \mathrm{~g} / \mathrm{m}^{2}\right)$, followed by $\operatorname{spring}\left(12.01 \mathrm{~g} / \mathrm{m}^{2}\right)$ and autumn $\left(8.37 \mathrm{~g} / \mathrm{m}^{2}\right)$, and lowest in $\operatorname{summer}\left(5.02 \mathrm{~g} / \mathrm{m}^{2}\right)$. The annual average value of Shannon-Wiener diversity index and Margalef diversity index was 2.19 and 1.34 , respectively. Correlation analyses indicated that water depth was the key factor influencing the standing crops of the benthic macroinvertebrates in this lake.

Keywords: Lake Ulungur; benthic macroinvertebrate; community structure; diversity index; correlation analysis

* 新疆福海县政府课题和国家科技支撑计划项目 (2006BAD03B02) 联合资助. $2010-11-03$ 收稿; 2011-02-17 收 修改稿. 赵永晶,女, 1984 年生, 硕士研究生; E-mail: yongjing0925@163.com.

** 通讯作者;E-mail:jzhsh@ mail. hzau. edu. cn. 
乌伦古湖 $\left(46^{\circ} 52^{\prime}-47^{\circ} 28^{\prime} \mathrm{N}, 87^{\circ} 00^{\prime}-87^{\circ} 30^{\prime} \mathrm{E}\right)$ 位于新疆最北端阿勒泰地区中部, 北依阿勒泰山脉, 南跨 准噶尔盆地至古尔班通古特沙漠. 乌伦古湖由布伦托海 (蒙语称 “大海子”. 海子: 方言, 湖) 和吉力湖 (俗称 “小海子”)组成,是全国十大内陆淡水湖之一, 同时也是新疆维吾尔自治区的第二大湖泊和主要的渔业基 地. 近年来, 受渔业生产活动、水利工程和气候变化影响, 加之乌伦古湖水循环缓慢, 乌伦古湖来水减少、水 位下降、矿化度增加, 营养水平提高 ${ }^{[1]}$.

大型底栖动物在水生态系统的物质循环和能量流动中起着重要的作用 ${ }^{[2]}$. 底栖动物除部分自身具有很 高的经济价值外, 还是鱼类的天然活饵料, 也是环境监测的指示生物 ${ }^{[3]}$. 目前对底栖动物的研究很多, 内容 主要涉及群落结构、生物多样性、水质评价、生产力、能量流动和生态模型 ${ }^{[4-10]}$ 等.

吴天惠和叶尚明等分别在 $1985-1987$ 年 ${ }^{[11]}$ 和 $2001-2002$ 年 ${ }^{[12]}$ 期间对乌伦古湖的底栖动物做过调查. 本文通过 2006 年 11 月 - 2008 年 7 月按季度对乌伦古湖底栖动物进行取样调查,分析其群落结构、分布规 律及其生物多样性, 以期为该湖渔业资源的合理利用和渔业的可持续发展提供依据,为建立乌伦古湖生态 学档案积累资料.

\section{1 采样点与研究方法}

\section{1 研究地点的设置和采样时间}

调查方法参照《湖泊生态调查观测与分析》 ${ }^{[13]}$ 及《内陆水域渔业自然资源调查手册》 ${ }^{[14]}$, 并根据 乌伦古湖的形态、水深、底质等环境特征, 在湖中心 区、沿岸区、主要进出水口等地,采用 GPS 定位共设 置 28 个采样点. 其中 $1^{\#}-25^{\#}$ 采样点位于布伦托 海, 布伦托海包括五个区域: $1^{\#}$ 和 $2^{\#}$ 位于中海子, $11^{\#}$ 和 $12^{\#}$ 位于 $73 \mathrm{~km}$ 小海子, $13^{\#}-15^{\#}$ 位于骆驼脖 子, $18^{\#}$ 和 $19^{\#}$ 位于海滨浴场, $3^{\#}-10^{\#} 、 16^{\#} 、 17^{\#}$ 、 $20^{\#}-25^{\#}$ 位于大海子, $26^{\#}-28^{\#}$ 位于吉力湖 (图 1 ). 本次调查从 2006 年 11 月开始,截止到 2008 年 7 月,每季度采样一次,共采样八次.

\section{2 底栖动物样品的采集及处理}

采样工具为 $1 / 16 \mathrm{~m}^{2}$ 彼得森采泥器, 每个采样 点采样 2 次, 然后用 40 目的网篮分选样品. 现场记 录各采样点环境因素, 如底质、水深、水草分布状 况和透明度等. 在白瓷盘中挑选出样品后, 计数称 重, 换算成密度 (ind. $\left./ \mathrm{m}^{2}\right)$ 和生物量 $\left(\mathrm{g} / \mathrm{m}^{2}\right)$. 水生 昆虫和软体动物用 $75 \%$ 的酒精固定, 寡毛类先用 $4 \%-10 \%$ 的甲醛溶液固定, $24 \mathrm{~h}$ 后移到 $70 \%$ 酒精 中保存. 标本鉴定参照国内外相关工具书 进行 ${ }^{[15-19]}$.

\section{3 数据分析方法}

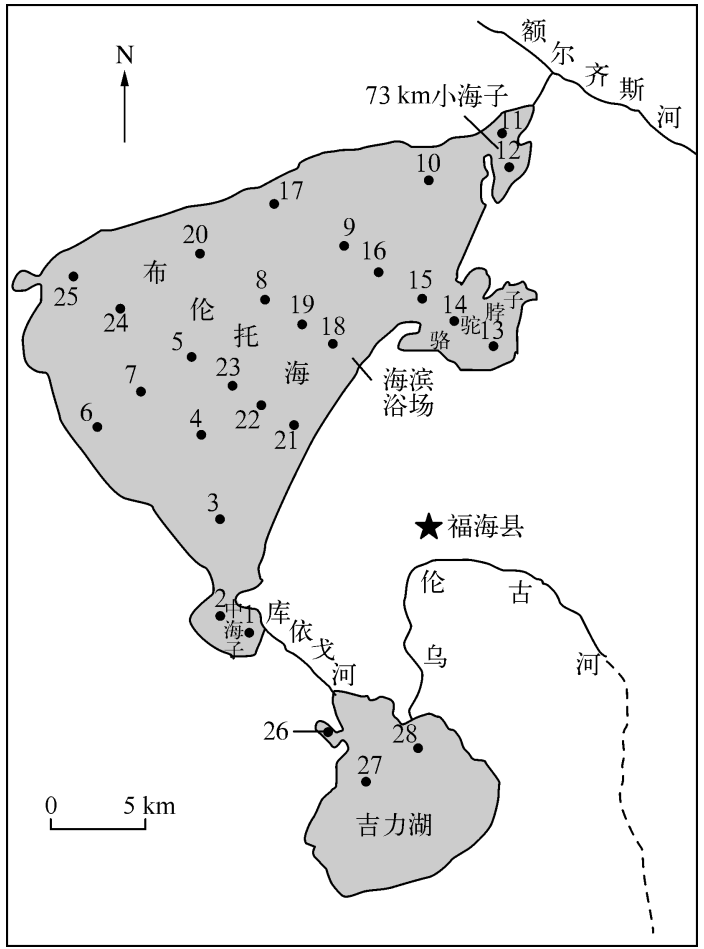

图 1 乌伦古湖采样点分布

Fig. 1 The sampling stations in Lake Ulungur

生物多样性指数提供了更多有关群落方面的信息, 可以用来指示环境的变换 ${ }^{[20]}$. 本研究采用 ShannonWiener 多样性指数: $H^{\prime}=-\sum_{i=1}^{S}\left(n_{i} / N\right) \lg \left(n_{i} / N\right)$ 和 Margalef 丰富度指数: $d_{\mathrm{M}}=(S-1) / \ln N, N$ 为样本中大 型底栖动物所有种类总个体数, $S$ 为样品中物种种类总数, $n_{i}$ 为第 $i$ 种物种的个体数. 数据处理分析采用 $\mathrm{Ex}-$ cel 和 SPSS 17.0 软件进行.

\section{4 优势种的确定}

底栖动物优势度的计算采用如下公式:优势度: $Y=\left(n_{i} / N\right) \times f_{i}$, 式中, $n_{i}$ 为第 $i$ 种的个体数, $N$ 为所有种 
类总个体数, $f_{i}$ 为出现频率. $Y$ 值大于 0.02 的种类定为为优势种 ${ }^{[21]}$.

\section{2 结果与分析}

乌伦古湖湖面海拔 $478 \mathrm{~m}$, 咜水 $77.4 \times 10^{8} \mathrm{~m}^{3}$, 水面面积 $917 \mathrm{~km}^{2}$. 湖区气候寒冷, 干燥少雨, 日照时间长, 霜冻期长, 年平均气温 $3.4^{\circ} \mathrm{C}$, 年平均蒸发量 $(1844.4 \mathrm{~mm})$ 是降水量 $(116.5 \mathrm{~mm})$ 的 15.8 倍, 年日照时数 $2881.2 \mathrm{~h}$, 无霜期 $147 \mathrm{~d}^{[22]}$. 本次研究表明, 乌伦古湖平均水深 $8.01 \pm 1.08 \mathrm{~m}$, 透明度年平均值为 $2.53 \pm 1.07 \mathrm{~m}$, 叶绿素 $\mathrm{a}$ 年平均值为 $3.59 \pm 18.34 \mathrm{mg} / \mathrm{m}^{3}$, 高锰酸盐指数年平均值为 $5.423 \pm 1.369 \mathrm{mg} / \mathrm{L}$, 总 氮年平均值为 $0.856 \pm 0.205 \mathrm{mg} / \mathrm{L}$, 总磷年平均值为 $0.028 \pm 0.033 \mathrm{mg} / \mathrm{L}$.

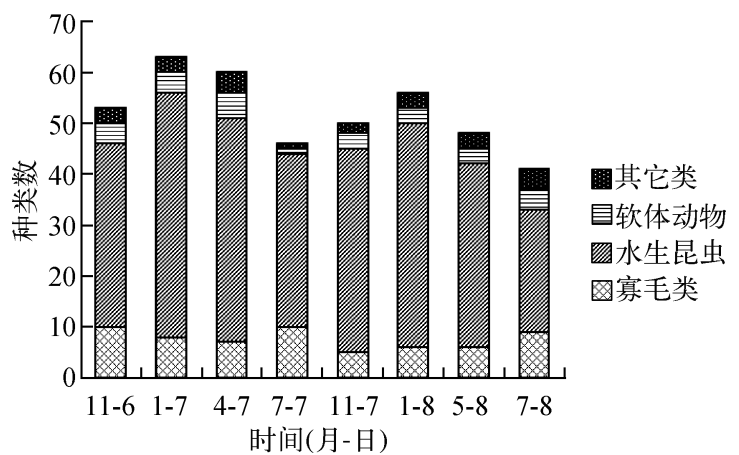

图 2 乌伦古湖大型底栖动物种类数及其季节变动

Fig. 2 The benthic macroinvertebrates species number and seasonal variations in Lake Ulungur

\section{1 大型底栖无脊椎动物种类组成}

2.1 .1 种类组成 2006 年 10 月- 2008 年 7 月调 查共采集到大型底栖动物 87 种. 其中水生昆虫 61 种, 占种类总数的 $70.1 \%$,寡毛类 14 种, 占总 种数 $16.2 \%$, 软体动物 7 种, 占总种数的 $8.0 \%$, 其它类仅 5 种,占总种数的 $5.7 \%$.

2.1 .2 种类组成季节变动 $2006-2007$ 年与 2007 年 -2008 年乌伦古湖大型底栖动物种类数季节变 化趋势一致,主要表现为冬季种类数 (1 月份) 最 多,其次为秋季 (11 月份)、春季 (4 月份) 和夏季 (7 月份) (图 2).

从优势种周年动态变化来看, 乌伦古湖没有 出现全年均占优势的类群,各季节间优势类群有 所不同. 春季底栖动物优势类群为水丝蚓一种

(Limnodrilus sp. ). 夏季底栖动物优势类群包括颤蚓一种 (Tubifex sp.) 、水丝蚓一种 (Limnodrilus sp.) 和喜盐 摇蚊 (Chironomus salinarius). 秋季底栖动物的优势类群包括摇蚊属一种 (Chironomus sp.) 和多足摇蚊属一种 (Polypedilum flavum). 冬季底栖动物优势类群包括喜盐摇蚊 (Chironomus salinarius) 和摇蚊属一种 (Chironomus sp.).

\section{2 大型底栖无脊椎动物的密度和生物量}

乌伦古湖大型底栖动物年平均密度为 $1015.01 \mathrm{ind} . / \mathrm{m}^{2}$, 主要由水生昆虫和寡毛类组成, 分别占 $49.58 \%$ 和 $47.57 \%$, 而软体动物和其它类所占比例较小, 仅占 $1.78 \%$ 和 $1.07 \%$ (图 3a). 底栖动物年平均生物量 $9.83 \mathrm{~g} / \mathrm{m}^{2}$, 主要由水生昆虫组成, 占 $88.20 \%$, 其次为塞毛类, 占 $4.27 \%$, 软体动物和其它类分别占 $3.87 \%$ 、 $3.66 \%$ (图 3b).

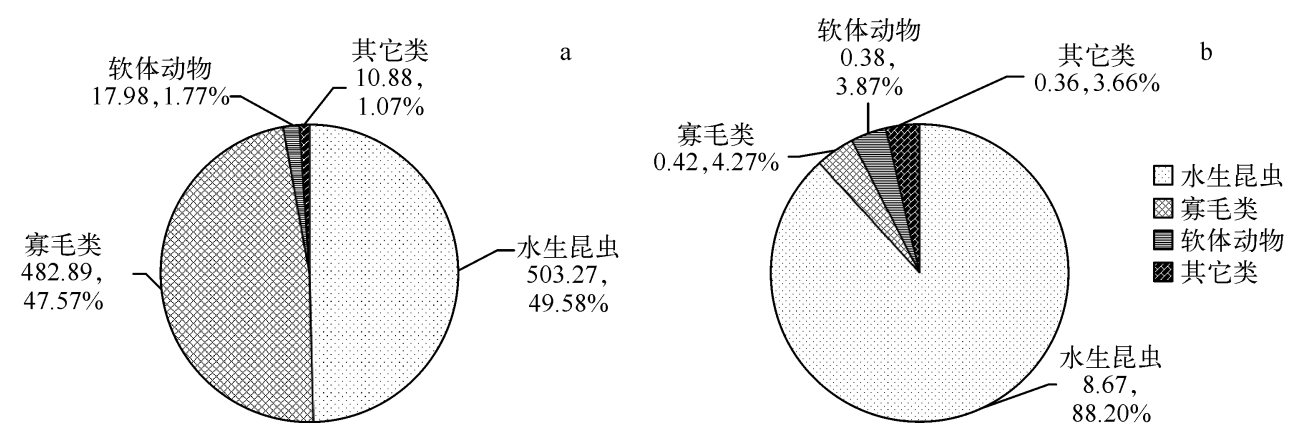

图 3 乌伦古湖底栖动物各类群密度 $\left(\right.$ ind. $\left./ \mathrm{m}^{2}\right)(\mathrm{a})$ 和生物量 $\left(\mathrm{g} / \mathrm{m}^{2}\right)(\mathrm{b})$ 组成

Fig. 3 Comparison of density and biomass of different benthic macroinvertebrate taxas in Lake Ulungur 
2.2.1 大型底栖动物的密度和生物量的季节变化 乌伦古湖各季度大型底栖动物的年均密度表现为冬季 (1 月份) $\left(1234.96 \mathrm{ind} . / \mathrm{m}^{2}\right)>$ 春季 $(5$ 月份 $)\left(1044.47 \mathrm{ind} . / \mathrm{m}^{2}\right)>$ 秋季 $(11$ 月份 $)\left(931.16 \mathrm{ind} . / \mathrm{m}^{2}\right)>$ 夏季 $(7$ 月份) $\left(849.44 \mathrm{ind} . / \mathrm{m}^{2}\right)$ ( 图 $\left.4 \mathrm{a}\right)$.

乌伦古湖各季度大型底栖动物的生物量表现为冬季 $\left(13.54 \mathrm{~g} / \mathrm{m}^{2}\right)>$ 春季 $\left(12.01 \mathrm{~g} / \mathrm{m}^{2}\right)>$ 秋季 $\left(8.37 \mathrm{~g} / \mathrm{m}^{2}\right)>$ 夏季 $\left(5.02 \mathrm{~g} / \mathrm{m}^{2}\right)$. 全年均为水生昆虫所占比例最大,但各季节所占比例有所不同,夏季最 高, 为 $96.1 \%$, 春秋季次之, 分别为 $93.9 \%$ 和 $89.8 \%$, 冬季最小, 为 $66.8 \%$ (图 $4 \mathrm{~b}$ ).
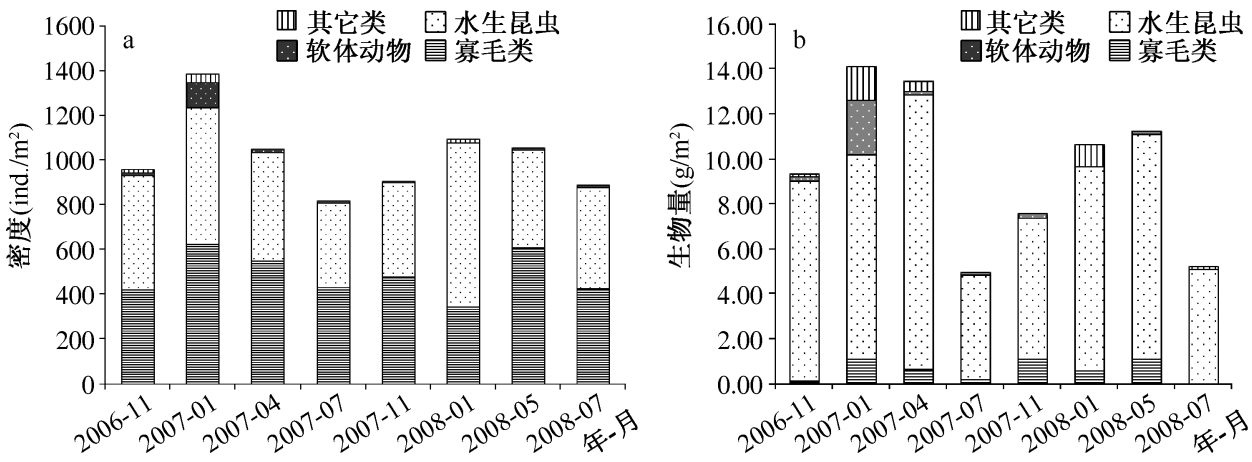

图 4 乌伦古湖大型底栖动物密度 $(\mathrm{a})$ 和生物量 $(\mathrm{b})$ 的季节变化

Fig. 4 The seasonal variations of $\operatorname{density}(\mathrm{a})$ and biomass(b) of benthic macroinvertebrates in Lake Ulungur

\section{2 .2 大型底栖动物密度和生物量的空间} 分布 乌伦古湖底栖动物的总体密度和生 物量由于采样点底质、水深等不同而分布 不均 ( 图 5 ). $5^{\#} 、 6^{\#} 、 7^{\#} 、 9^{\#} 、 10^{\#} 、 11^{\#} 、 14^{\#}$ 、

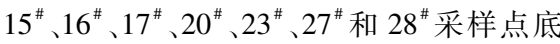
质多为淤泥、软泥, 可采到水草, 底栖动物 尤其是摇蚊幼虫密度和生物量较高, 密度 变化幅度为 $366-1216$ ind. $/ \mathrm{m}^{2}$, 生物量变 化幅度为 $11.18-26.26 \mathrm{~g} / \mathrm{m}^{2}$, 其它种类如 钩虾和螺类也有一定数量分布, 其中 $17^{\#}$ 钩 虾、螺类年平均密度达 1189 ind. $/ \mathrm{m}^{2}$, 年平 均生物量达 $19.05 \mathrm{~g} / \mathrm{m}^{2} .6^{\#}$ 水草丰富, 主要 由软体动物和钩虾组成, 在冬季, 钩虾密度 达到了 $1320 \mathrm{ind} . / \mathrm{m}^{2}$, 生物量达到了 $40.03 \mathrm{~g} / \mathrm{m}^{2}$, 该处底栖动物年均生物量也 是最大的, 达 $26.26 \mathrm{~g} / \mathrm{m}^{2}$, 是全湖年平均生 物量的 5 倍. $1^{\#} 、 2^{\#} 、 8^{\#} 、 13^{\#} 、 15^{\#} 、 18^{\#} 、 19^{\#}$ 、

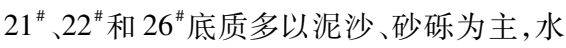
草较少或无, 底栖动物的密度和生物量均 较小, 密度变化幅度为 $68-485$ ind. $/ \mathrm{m}^{2}$, 生 物量变化幅度为 $0.47-2.29 \mathrm{~g} / \mathrm{m}^{2} .3^{\#} 、 4^{\#}$ 、

$24^{\#}$ 和 $25^{\#}$ 采样点相对于其它样点寡毛类所占比例较大, 由于寡毛类个体极小, 对生物量的贡献也较小, 因此 表现为密度高, 为 $780-1270 \mathrm{ind} . / \mathrm{m}^{2}$, 而生物量较低, 为 $0.45-13.18 \mathrm{~g} / \mathrm{m}^{2}$.

\section{3 大型底栖无脊椎动物的物种多样性}

乌伦古湖大型底栖动物 Shannon-Wiener多样性指数和 Margalef 丰富度指数均较高, 季节变化表现为冬 


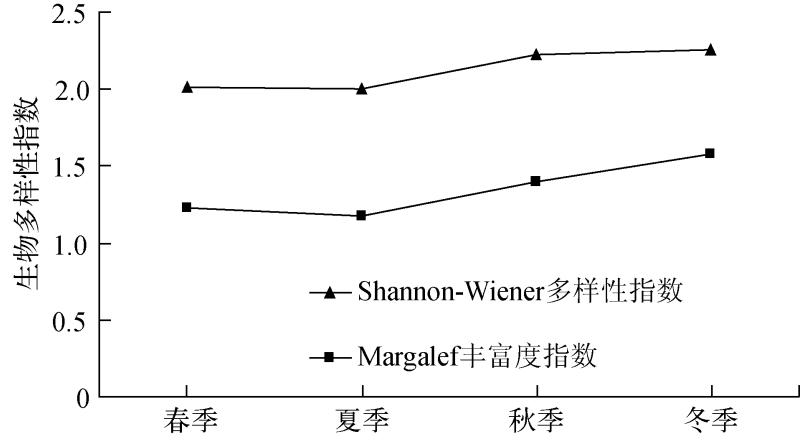

图 6 乌伦古湖底栖动物生物多样性的季节变化

Fig. 6 Seasonal changes of biodiversity index of benthic macroinvertebrates in Lake Ulungur
季 $>$ 秋季 $>$ 春季 $>$ 夏季 $($ 图 6).

\section{4 大型底栖无脊椎动物与环境因子之间 的相关分析}

为了解不同环境因子对乌伦古湖大型 底栖动物群落结构的影响, 将底栖动物密度 和生物量与水深、溶解氧、水体总氮、总磷、 叶绿素 $\mathrm{a} 、$ 钻离子、氯离子、硬度、碱度 9 个理 化因子进行 Pearson 相关分析, 结果表明底 栖动物密度与水深呈显著负相关 $(P<$ $0.05, n=28)$, 生物量与水深呈极显著负相 关 $(P<0.01, n=28)$, 与其他因子无显著相 关关系 $(P>0.05, n=28)$ (表 1$)$.

表 1 乌伦古湖大型底栖无脊椎动物密度、生物量与理化因子的相关分析 $(n=28)$

Tab. 1 Correlations between density and biomass of benthic macroinvertebrates and the physical-chemicalfactors in Lake Ulungur

\begin{tabular}{ccccccccccc}
\hline 指标 & & 水深 & 溶解氧 & 总氮 & 总磷 & 叶绿素 $\mathrm{a}$ & 钙离子 & 氯离子 & 硬度 & 碱度 \\
\hline 密度 & 相关系数 & $-0.266^{*}$ & 0.146 & 0.013 & 0.057 & 0.186 & 0.130 & 0.175 & 0.190 & 0.031 \\
& $P$ (双尾) & 0.032 & 0.318 & 0.867 & 0.524 & 0.052 & 0.059 & 0.438 & 0.056 & 0.804 \\
\multirow{2}{*}{ 生物量 } & 相关系数 & $-0.351^{* *}$ & 0.122 & 0.079 & -0.147 & 0.017 & 0.261 & 0.077 & 0.211 & 0.152 \\
& $P$ (双尾 $)$ & 0.000 & 0.726 & 0.828 & 0.685 & 0.853 & 0.466 & 0.833 & 0.132 & 0.176 \\
\hline
\end{tabular}

\section{3 讨论}

\section{1 乌伦古湖底栖动物群落结构的时空变化}

乌伦古湖大型底栖动物的群落结构存在明显的季节性变化, 种类数呈现冬季 $>$ 秋季 $>$ 春季 $>$ 夏季. 四 季均出现的种类仅 25 种, 如正颤蚓 (Tubifex tubifex)、水丝蚓、喜盐摇蚊、摇蚊属一种、指突隐摇蚊 (Cryptochironomus digitatus)、前突摇蚊 (Procladius sp.)、梯形多足摇蚊 (Polypedilum scalaenum) 和钩虾 (Gammarus sp. ) 等为乌伦古湖的常见种. 某些种类的出现具有明显的季节性, 如管水蚓 (Aulcarilus sp. ) 仅在秋冬季出现, 湖 北三道河水库观察到相似现象 ${ }^{[23]}$.

乌伦古湖大型底栖动物密度和生物量的季节变化呈现冬季 $>$ 春季 $>$ 秋季 $>$ 夏季的趋势. 这与陈立婧等

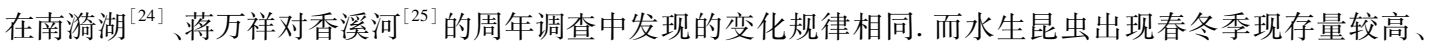
夏秋季节较低的现象, 可能与乌伦古湖主要水生昆虫种类一一摇蚊科幼虫夏秋季大量羽化有关. 郭先武研 究武汉南湖摇蚊群落的种群变动规律时发现摇蚊幼虫数量高峰出现在春、冬两季 ${ }^{[26]}$, 乌伦古湖摇蚊类幼虫 的季节变动规律与其一致. 软体动物的密度和生物量的年变化与其生活史规律及鱼类摄食强度变化有关, 3-10月是螺类的繁殖期, 6-7 月达到高峰期, 而 6-7 月又是鱼类摄食的高峰期, 鱼类摄食大量的螺类, 导 致了螺类的密度和生物量明显降低; 以后随着螺类的大量繁殖和生长, 其密度和生物量又不断增加, 与此同 时鱼类的摄食能力逐渐下降, 导致软体动物的密度和生物量在冬季达最大值, 2006 年冬季软体动物的密度 分别为 101.34 ind. $/ \mathrm{m}^{2}$ 和 $2.09 \mathrm{~g} / \mathrm{m}^{2}$.

乌伦古湖底栖动物群落结构在空间上也呈现出明显差异. 软体动物分布在沿岸带和一些有水草分布的

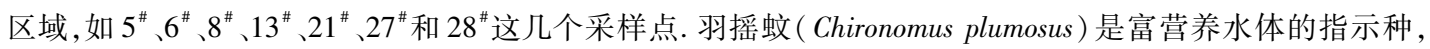
仅在骆驼脖子和吉力湖出现, 这可能与这两个区域局部富营养化程度较高有关; 毛翅目、蜉蝣目、蜻蜓目等 仅在中海子和 $21^{\#}$ 采样点出现; 瑞士水丝蚓 (Limnodrilus helveticus) 和双突杆吻虫 (Stylaria lacustris) 这两种寡 毛类的分布范围可能仅限于全北区, 但前者分布于各湖区, 而双突杆吻虫仅在小海子和中海子出现. 位于吉 
力湖的 $27^{\#}$ 和 $28^{\#}$ 采样点寡毛类平均密度高达 $2608 \mathrm{ind} . / \mathrm{m}^{2}$, 是全湖寡毛类平均密度的 6 倍, 这与寡毛类喜粒 径小、有机质丰富的底质 ${ }^{[27]}$ 有关, 吉力湖为养殖公司承包开展鱼类增养殖, 其有机质含量丰富, 富营养化程 度较高, 有机质含量的增加会引起葟毛类尤其是颤蚓科密度和生物量水平的升高 ${ }^{[28]}$. 但值得注意的是被承 包用来养鲢、鳙鱼种的后泡子由于大量投放未经腐熟的牛羊粪, 底质有机污染严重, 位于其中的 $26^{\#}$ 采样点 不论种类、还是密度和生物量均很低.

将本研究 2007 和 2008 年 7 月的数据与吴天惠 1985 年 7 月的研究结果 ${ }^{[11]}$ 进行比较可以看出, 20 多年来, 乌伦古湖底栖动物在种类及数量上发生了较大的变化. 种类从 1985 年的 69 种减少到 2007 年的 46 种和 2008 年的 41 种, 密度由 1083.71 ind. $/ \mathrm{m}^{2}$ 减少到 810.55 ind. $/ \mathrm{m}^{2}$ 和 888.32 ind. $/ \mathrm{m}^{2}$, 生物量由 $18.544 \mathrm{~g} / \mathrm{m}^{2}$ 减少到 $4.509 \mathrm{~g} / \mathrm{m}^{2}$ 和 $5.528 \mathrm{~g} / \mathrm{m}^{2}$ (表 2).

表 21985 年, 2007 年和 2008 年夏季乌伦古湖底栖动物现存量的变化

Tab. 2 Standing-crops of benthic macroinvertebrates in summers of 1985, 2007 and 2008 in Lake Ulungur

\begin{tabular}{|c|c|c|c|c|c|c|}
\hline 指标 & 年份 & 塞毛类 & 水生昆虫 & 软体动物 & 其它类 & 总计 \\
\hline \multirow[t]{3}{*}{ 种类数 } & 1985 & 9 & 42 & 11 & 7 & 69 \\
\hline & 2007 & 10 & 34 & 1 & 1 & 46 \\
\hline & 2008 & 9 & 24 & 4 & 4 & 41 \\
\hline \multirow[t]{3}{*}{ 密度 (ind. $/ \mathrm{m}^{2}$ ) } & 1985 & 115.08 & 934.33 & 32.29 & 2.01 & 1083.71 \\
\hline & 2007 & 428.85 & 378.28 & 3.14 & 0.28 & 810.55 \\
\hline & 2008 & 420.88 & 456.40 & 1.68 & 9.36 & 888.32 \\
\hline \multirow[t]{3}{*}{ 生物量 $\left(\mathrm{g} / \mathrm{m}^{2}\right)$} & 1985 & 0.181 & 11.537 & 6.814 & 0.012 & 18.544 \\
\hline & 2007 & 0.252 & 4. 231 & 0.025 & 0.001 & 4. 509 \\
\hline & 2008 & 0.232 & 5.192 & 0.048 & 0.056 & 5.528 \\
\hline
\end{tabular}

乌伦古湖大型底栖动物群落组成上的具体变化表现为以下两个方面:一是寡毛类的密度增加了近 3 倍,这可能与有机质含量的增加有关;二是水生昆虫和软体动物的种类和现存量显著下降. 1950s 中海子、骆 驼脖子及乌伦古湖三角洲地带有几万亩的芦苇丛, 由于人为砍伐, 围层造田, 毁草造地, 水域环境发生变化, 1970s 以来芦苇丛逐渐消失, 被低矮芦苇和杂草替代 ${ }^{[29]}$. 中海子、骆驼脖子及吉力湖北部浅水区原有的近十 万亩眼子菜、金鱼藻等沉水植物消亡. 软体动物腹足类喜生活于水质较好、水生植物较多的水域内, 以水生 藻类及水生植物为食, 当水生植物缺乏、水质变差时,这些种类便会大大减少. 另外, 无齿蚌的消失可能与底 质有关. 有研究表明, 淤泥沉凝和泥沙覆盖也会造成双壳类底栖动物窒息而死, 特别是对幼贝的危害 更大 ${ }^{[30]}$.

\section{2 乌伦古湖底栖动物群落结构特点}

与长江流域中下游湖泊 (如鄱阳湖和扁担塘) 相比, 乌伦古湖底栖动物群落具有种类偏少, 密度略高, 生 物量低的特点 (表 3 ). 鄱阳湖为我国第一大淡水湖泊, 且为通江湖, 湖泊发育比较完全,据谢钦铭等 ${ }^{[31]}$ 调查 发现, 鄱阳湖瓣鳃类的种类就高达 52 种,底栖动物种类 95 种, 而本次乌伦古湖底栖动物的调查中仅发现无 齿蚌一种. 扁担塘为典型的草型浅水湖泊, 几乎全湖都有水生植物分布, 为底栖动物尤其是软体动物提供了 良好的栖息生存环境 ${ }^{[32]}$. 乌伦古湖岸带发育不完全, 缺少大型挺水植物, 而沉水植物的分布也在逐渐减少, 导致寡毛类和水生昆虫成为明显优势类群, 而软体动物种类和数量较少.

洱海与新疆乌伦古湖同属于中等深水湖泊. 洱海有一定程度的富营养化, 营养水平较乌伦古湖高, 为底栖 动物提供了丰富的食物来源, 且沉水植物分布占全湖的 $40.39 \%$, 为软体动物的生长繁殖提供了良好的环境 ${ }^{[33]}$. 乌伦古湖目前属于中营养型湖泊 ${ }^{[38]}$, 相比之下密度和生物量较低. 此外, 水温条件也可能是两者差异的原因.

博斯腾湖与乌伦古湖分别为新疆第一、第二大湖, 平均水深均为 $8 \mathrm{~m}$, 同样缺乏水生植物 ${ }^{[22]}$. 但比较而言, 乌伦 古湖底栖动物种类、密度和生物量明显高于博斯腾湖 (表 3). 造成差异的原因可能与博斯腾湖污染程度较高有关, 但也可能与两者水体营养物质、底质状况等理化因子存在差异有关. 
表 3 不同湖泊底栖动物的种类、密度和生物量*

Tab. 3 Comparison of category, density and biomass of benthic macroinvertebrates between Lake Ulungur and other lakes in China

\begin{tabular}{|c|c|c|c|c|c|c|}
\hline 指标 & 湖泊 & 寡毛类 & 水生昆虫 & 软体动物 & 其它类 & 总计 \\
\hline \multirow[t]{5}{*}{ 种类数 } & 乌伦古湖 & 14 & 61 & 7 & 5 & 82 \\
\hline & 鄱阳湖 [40] & 12 & 17 & 66 & -- & 95 \\
\hline & 扁担塘 [41] & 29 & 32 & 17 & 10 & 88 \\
\hline & 洱海 $^{[43]}$ & -- & -- & -- & - & 30 \\
\hline & 博斯腾湖 [36] & 4 & 12 & 3 & - & 19 \\
\hline \multirow[t]{5}{*}{ 密度 (ind. $/ \mathrm{m}^{2}$ ) } & 乌伦古湖 & 482.89 & 503.27 & 17.98 & 10.88 & 1015.01 \\
\hline & 鄱阳湖 & 56 & 90 & 578 & -- & 724 \\
\hline & 扁担塘 & 143 & 344 & 294 & 59 & 840 \\
\hline & 洱海 & 370 & 203 & 646 & - & 1219 \\
\hline & 博斯腾湖 & -- & -- & -- & - & 227 \\
\hline \multirow[t]{5}{*}{ 生物量 $\left(\mathrm{g} / \mathrm{m}^{2}\right)$} & 乌伦古湖 & 0.42 & 8.67 & 0.38 & 0.36 & 9.83 \\
\hline & 鄱阳湖 & 0.58 & 0.959 & 248.70 & -- & 250.24 \\
\hline & 扁担塘 & -- & -- & -- & -- & 40.03 \\
\hline & 洱海 & 37.17 & 15.41 & 5.43 & - & 58.01 \\
\hline & 博斯腾湖 & -- & -- & -- & - & 0.86 \\
\hline
\end{tabular}

* - - 表示数据缺失,一表示未出现.

\section{3 环境因子与底栖动物现存量的时空变化}

在不同水体中, 底栖动物群落结构的变化受不同环境因子的影响. 本次调查分析表明, 水深、底质和水 草是影响乌伦古湖大型底栖动物群落变化的重要环境因子.

Pearson 相关分析表明, 底栖动物密度与水深呈显著负相关 $(P<0.05, n=28)$, 生物量与水深呈极显著 负相关 $(P<0.001, n=28)$. 马徐发等 ${ }^{[34]}$ 研究也表明, 水深是影响湖北道观水库大型底栖动物群落结构的重 要环境因子. 一般认为, 底栖动物密度和生物量有明显随着水深的增大而不断递减的现象. 国外一些学者在 华盛顿湖和 Borrevann 湖中发现, 底栖动物的现存量在湖泊中存在两个峰值, 一个是位于深水带, 另一个是 位于沿岸带 ${ }^{[35-36]}$. 本次调查, $14^{\#}$ 采样点年平均水深为 $19.4 \mathrm{~m}$, 是整个湖中所有采样点中最深的位置, $6^{\#}$ 采样 点位于沿岸带,这两处底栖动物生物量最大, 分别为 $27.13 \mathrm{~g} / \mathrm{m}^{2}$ 和 $25.87 \mathrm{~g} / \mathrm{m}^{2}$.

陈其羽等认为, 底栖动物特别是寡毛类和摇蚊幼虫在不同底质中的现存量分布顺序是腐泥 $>$ 软泥 $>$ 粘 土 $>$ 砂 ${ }^{[37]}$. 在乌伦古湖, $10^{\#} 、 11^{\#} 、 14^{\#} 、 17^{\#}$ 和 $20^{\#}$ 采样点底质为淤泥、软泥, 摇蚊幼虫密度和生物量较大, 如 $14^{\#}$ 采样点春季和冬季均达到了 $1600 \mathrm{ind} . / \mathrm{m}^{2}$ 以上, 生物量也超过了 $50 \mathrm{~g} / \mathrm{m}^{2} .27^{\#}$ 、28 采样点位于吉力湖, 底 质多为淤泥并混有少量泥沙, 浅水区水草较多,塞毛类的数量较多,冬季密度曾达到 $5600 \mathrm{ind} . / \mathrm{m}^{2}$.

本研究发现寡毛类和摇蚊幼虫在全湖均有分布, 而软体动物萝卜螺属的某些种类, 毛翅目、蜉蝣目、蜻 蜓目和鞘翅目等水生昆虫, 以及钩虾主要分布在芦苇、眼子菜等水生植物比较丰富的区域, 这些区域具有较 高的空间异质性, 为底栖动物提供了栖息、生活、摄食、繁殖以及良好的隐蔽的场所. 由此可见, 水生植物在 维持底栖动物多样性方面具有重要作用. 要恢复乌伦古湖大型底栖动物的生物多样性和生物量, 应当设法 恢复水生植被等适于软体动物等底栖动物生存繁衍的生境, 以提高乌伦古湖生态系统的生态完整性.

致谢: 中国科学院水生生物研究所王洪铸研究员, 崔永德老师和何雪宝博士在底栖动物种类鉴定方面提供 了帮助, 谨表谢意!

\section{4 参考文献}

[ 1 ] 谢立新. 乌伦古湖泊水位及水质变化原因分析. 水资源与水工程学报, 2009, 20(2) : 148-152.

[ 2 ] Beche LA, Mcelravy EP, Resh VH. Long-term seasonal variation in the biological traits of benthic-macroinvertebrates in two Mediterranean-climate streams in California, U. S. A. Freshwater Biology, 2006, 51: 56-75.

[ 3 ] Beat Oertli. Spatial and temporal distribution of the zoobenthos community in a woodland pond. Hydrobiologia, 1995,300 : 
195-204.

[ 4 ] 陈其羽, 梁彦龄, 宋贵保等. 武昌东湖软体动物的生态分布及种群密度. 水生生物学集刊, 1975, 5(3): 371-379.

[ 5 ] 杨俊毅, 高爱根, 宁修仁等. 乐清湾大型底栖生物群落特征及其对水产养殖的响应. 生态学报, 2007, 27 (1) : $34-41$.

[ 6 ] 熊 飞, 李文朝, 潘继征. 高原深水湖泊抚仙湖大型底栖动物群落结构及多样性. 生物多样性, 2008, 16 (3) : 288-297.

[ 7 ] 戴友芝, 唐受印, 张建波. 洞庭湖底栖动物种类分布及水质生物学评价. 生态学报, 2000, 20(2): 277-282.

[8] 间云君, 梁彦龄. 扁担塘底栖动物群落的能量流动. 生态学报, 2003, 23(3) : 527-538.

[9] 间云君, 梁彦龄. 草型湖泊与藻型湖泊大型底栖动物生产力的比较. 湖泊科学, 2004, 16(1): 81-84.

[10] Lars H, Viktor VB. Modelling production and biomasses of zoobenthos in lakes. Aquatic Ecology, 2003, 37: 277-306.

[11] 吴天惠. 新疆福海底栖动物的研究. 水生生物学报, 1991, 15(4) : 303-313.

[12］叶尚明, 苏德学, 刘 栓等. 新疆乌伦古湖水生生物资源调查研究. 水利渔业, 2004, 24(2) : 51-53.

[13］黄祥飞. 湖泊生态调查观测与分析. 北京: 中国标准出版社, 1999: 72-79.

[14] 张觉民，何志辉. 内陆水域渔业自然资源调查手册. 北京: 农业出版社, 1991 .

[15] Epler JH. Identification manual for the larval Chironomidae(Diptera) of North and South Caroline. EPA, Human Health and Ecological Criteria Division, 2001.

[16] Morse JC, Yang L, Tian L. Aquatic insects of China useful for monitoring water quality. Nanjing: Hohai University Press, 1994.

[17] Fitter R, Manuel R. Lakes, rivers, streams \& ponds of Britain \& North-West Europe. London: Harper Collins, $1994,369$.

[18] 陈心陶，陈 义，齐钟彦等. 中国动物图谱. 北京: 科学出版社, 1959.

[19］王洪铸. 中国小蚓类研究——附南极长城站附近地区两新种. 北京: 高等教育出版社, 2002.

[20］苏永春, 勾影波, 郁 达等. 江苏常熟虞山土壤动物群落多样性研究. 生物多样性, 2004, 12(3): 333-338.

[21] 沈国英, 施并章. 海洋生态学. 北京: 科学出版社, 2002.

[22] 汪宪栕, 王洪道, 张开翔等. 新疆乌伦古湖的自然条件及其渔业生物学基础的初步研究. 海洋湖沼通报, 1981, 4: $18-28$.

[23] 池仕运, 彭建华, 万成炎等. 湖北省三道河水库底栖动物的初步研究. 湖泊科学, 2009, 21(5) : 705-712.

[24] 陈立婧, 彭自然, 孙家平等. 安徽南渏湖大型底栖动物群落结构. 动物学杂志, 2008, 43(1): 63-68.

[25] 蒋万祥, 蔡庆华, 唐 涛等. 香溪河大型底栖无脊椎动物空间分布. 应用生态学报, 2008, 19(11) : 2443-2448.

[26] 郭先武. 武汉南湖三种摇蚊幼虫生物学特征及其种群变动的研究. 湖泊科学, 1995, 7 (3):249-255.

[27] Matisoff G, Wang XS, McCall PL. Biological redistribution of lake sediments by tubficid oligochaetes: Branchiura sowerbyi and Limnodrilus hoffmeisteri/ Tubifex tubifex. Journal of Great Lakes Research, 1999, 25: 205-219.

[28 ] Perlta L, Escobar E, Alcocer J et al. Oligochaetes from six trophic crater lakes in Central Mexico: species composition, density and biomass. Hydrobiologia, 2002, 467 : 109-116.

[29］李文朝，杨清心. 乌伦古湖水生植被研究. 海洋与湖沼, 1993, 24(1) : 100-108.

[30］蔡英亚，张 英，魏若飞. 贝类学概论. 上海：上海科学技术出版社, 1979: 104-112.

[31] 谢钦铭, 李 云, 熊国根. 鄱阳湖底栖动物生态学研究及其底层鱼产力的估算. 江西科学, 1995, 13 (3) : 161-171.

[32] 间云君, 李晓宇, 梁彦龄. 草型湖泊与藻型湖泊大型底栖动物群落结构的比较. 湖泊科学, 2005, 17 (3): 176-182.

[33] 胡小贞, 金相灿, 杜宝汉等. 云南洱海沉水植被现状及其动态变化. 环境科学研究, 2005, 18: 1-4.

[34] 马徐发, 熊邦喜, 王明学等. 湖北道观河水库大型底栖动物的群落结构及物种多样性. 湖泊科学, 2004, 16(1): 49-55.

[35] Thut RN. A study of the profundal bottomfauna of lake Washington. Ecological Monographs, 1969, 39 : 79-100.

[36] Kland J. Theeutyophic Lake Borrevann (Norway) — an ecological study on shore and bottom fauna with special reference to gastrpods, including a hydrographic survey. Folia Limnol, Scandinavia, 1964, 13 : 337.

[37] 陈其羽, 梁彦龄, 吴天慧. 武汉东湖底栖动物群落结构和动态研究. 水生生物学集刊, 1980, 7(1): 41-56.

[38] 刘 宇, 沈建忠, 李 鸿等. 新疆乌伦古湖浮游植物群落结构. 湖泊科学, 2009, 21(6) : 855-864. 